\title{
Prevalence of Musculoskeletal Injuries in Males and Females Practicing Swimming from Higher School of Zimbabwe
}

\author{
Dube Adiele ${ }^{1,}$,, Gundani Patrick Morgan ${ }^{2}$ \\ ${ }^{1}$ Department of Emergency Medical Care, Emergency Medical Ambulances Rescue Services, Kwekwe, Zimbabwe \\ ${ }^{2}$ Department of Sports Science and Coaching, Faculty of Applied Sciences, National University of Science and Technology, Bulawayo, \\ Zimbabwe
}

Email address:

adieledube@yahoo.com (D. Adiele)

${ }^{*}$ Corresponding author

To cite this article:

Dube Adiele, Gundani Patrick Morgan. Prevalence of Musculoskeletal Injuries in Males and Females Practicing Swimming from Higher School of Zimbabwe. American Journal of Sports Science. Vol. 6, No. 1, 2018, pp. 8-11. doi: 10.11648/j.ajss.20180601.12

Received: January 16, 2017; Accepted: April 1, 2017; Published: January 17, 2018

\begin{abstract}
An epidemiological survey was conducted to collect data relating to the prevalence and frequency of musculoskeletal injuries in Zimbabwean high school male and female swimmers. A questionnaire was administered on site thus ensuring that the response rate was 100 percent. Analysis of results revealed that of the 45 respondents there were 22 male $(48.9 \%)$ and 23 female subjects $(51.1 \%)$. A total of 27 swimmers $(60 \%$ hence 16 male; 11 females); $59.26 \%$ and $40.74 \%$ respectively reported that they had musculoskeletal problems and pain mainly shoulder problems (males $=62 \%$ and females $=$ $57.1 \%$ ), followed by knee injuries (males $=20.6 \%$ and females $=16.7 \%$ ), and low back pain region (males $=17.1 \%$ and females $=26.2 \%)$. There was a statistical significance in injury difference between male and female high school swimmers $(\mathrm{t}=$ $2.46, \mathrm{p}=0.031)$. Considering the difference of injuries with respect to strokes significant injuries difference were found in Back Strokes ( $p=0.034)$ and Butterfly $(p=0.018)$. However, no significant difference were found in Breast Stroke ( $p=0.567)$ and Crawl $(\mathrm{p}=0.852)$. Musculoskeletal injuries are common in high school male and female swimmers. Correct stroke technique and stroke alterations may help to prevent injuries and care must be taken for their prevention and early safe return to play.
\end{abstract}

Keywords: Musculoskeletal Injuries, Sprain, Strain, Swimmers

\section{Introduction}

Swimming is an all ages unique sport which presents prophylactic and therapeutic value, with low risk of trauma stirring in an impact-free environment $[1,2]$. Swimming can be recreational, rehabilitation or a highly competitive sport which require high levels of training and performance, which can cause overuse on muscular skeletal system, causing injuries to swimmers. It requires a variety of physical attributes, stroke specific skills and combines both upper and lower extremity strength exercises with cardiovascular training [3-5, 13]. Freestyle, butterfly, backstroke, and breaststroke are the four strokes for competitive swimming. Regardless of the stroke performed during training or competition, participants are exposed to constant and intense stress, with highly repetitive motion that occurs in the normal swimming stroke which can cause pain or musculoskeletal injuries of the upper limb and lower limb [1, 5, 10, 26], hence decreasing sports performance and leading to early dropout. Coaches play an imperative role in recognising the early indicators of injury. Despite coaches' early intervention, constant and intense stress syndromes can be best prevented by appropriate and modified training programs; strength training, flexibility exercises, and altering stroke mechanics and technique.

Despite that the prevalence of musculoskeletal injuries in competitive swimmers has been described in the late $20^{\text {th }}$ century and identified more frequency in the shoulder, with $37 \%$ out of the total, followed by the knee, with $28 \%$, and the foot and ankle, both with $19 \%$ [6]. The author reported that musculoskeletal injuries in high school swimmers may be of trauma or secondary origin, by overtraining. Acute trauma 
injuries are rare and injuries by overtraining predominately occur in competitive athletes. Researchers still show that there is limited information which exists regarding the epidemiology of swimming injury patterns at the high school, collegiate, elite, amateur, and master's levels [2, 5, 7-10, 13, 28].

In Midlands province, Zimbabwe's central province lacks studies on the prevalence of injuries in swimmers and information regarding the epidemiology of musculoskeletal injury, for competitive swimming. Therefore, the purpose of the current study was to determine and analyze the pattern of injuries in competitive, Midlands, male and female high school swimmers over the course of 3 years.

\section{Methodology}

\subsection{Sample Size and Sampling}

From a total of 105 swimmers in the Midlands province, only 45 swimmers (22 boys and 23 girls) purposively recruited. Both boys and girls had mean age was $16.43 \pm 2.36$ years, weight of $55.01 \pm 6.14 \mathrm{~kg}$, height $168.34 \pm 9.81 \mathrm{~cm}$. BMI for boys was $19.31 \pm 1.22$ whilst girls had $20.05 \pm 1.73$. Average training age was $3.41 \pm 1.52$ years and training duration was $3.08 \pm 1.69$ hours. All recruited, were regular competitive swimmers in both provincial and national swimming championships during the period of 2013-2015. This was a cross-sectional study among high school children from the three government and two private high schools in Kwekwe and Gweru districts.

\subsection{Ethical Considerations}

Ethics approval for this study was obtained from the National University of Science and Technology (NUST) and permission to use the schools were obtained from the Ministry of Primary and Secondary Education, Midlands Province. The nature and scope of the study were explained to the swimmers and their parents/guardians who gave informed consent before investigation was conducted. Informed consent was obtained from each of the study participants and their parents or guardians, swimming coaches, team medics and school heads. Only swimmers with both written assent and consent were used as subjects in this study. The investigator personally contacted the heads of schools, team managers and coaches of the various high school and club teams to explain the purpose of this study.

\subsection{Data Collection}

A questionnaire prepared by Venancio B. O (2012) [5] for swimmers was adopted and modified by the investigator was given to the subjects for completion. The questionnaire had items covering both biological and training age, anthropometry, training type and volume, evaluation of the prevalence of the pain sites, possible injuries as well as sport injuries treatment and rehabilitation. Two research assistants, who were final-year students in the National University of Science and Technology (NUST), Sports Science and Coaching Department and had covered Biokinetics module participated in the data collection.

\subsection{Data Analysis}

Data was analysed using descriptive statistics. The Statistical Package for the Social Sciences, version 20.0 (SPSS Inc., Chicago, Illinois, USA) was used. The parametric t-test was applied to test significance level at $\mathrm{p}<$ 0.05 for male and female swimmers frequencies. $P$-value $<$ 0.05 was regarded as significant.

\section{Results}

Of these 45 swimmers, 27 swimmers (16 male; 11 females); $59.26 \%$ and $40.74 \%$ respectively reported musculoskeletal problems and pain in the shoulder, knee, or lower back region.

Table 1. Musculoskeletal problems and pain/injuries between High school Males and Female swimmers.

\begin{tabular}{lllll}
\hline Variable & $\mathbf{N}$ & Mean \pm sd & t-ratio & P-value \\
\hline Female & 11 & $1.39 \pm 0.22$ & $2.46^{*}$ & $0.031^{*}$ \\
Male & 16 & $1.46 \pm 0.34$ & & \\
\hline
\end{tabular}

*Significant correlations are flagged at $\mathrm{P}<0.05$

The obtained $\mathrm{t}=2.46$ was significant at.001 level, indicating that male swimmers had greater incidence of musculoskeletal problems and pain/injuries than their female counterparts.

The most complaints of musculoskeletal problems and pain/injuries were found related to pool training compared to dry land, cross and weight training; $72 \%$ and $28 \%$ respectively. More frequently musculoskeletal pain/injury problems were found to freestyle swimmers (59.6\%) compared to other strokes during both training and competition. Statistical information of incidence of injuries recorded in the high school male and female swimmers during competition and training periods showed that there was no significant difference in the occurrence of injuries in relation to both the competition and the training period.

Table 2. Injuries difference between Male and Female High school swimmers with respect to stroke.

\begin{tabular}{lllll}
\hline Male (16) & Female (11) & & & \\
\hline Stroke & Mean \pm sd & Mean \pm sd & t-ratio & P-value \\
\hline Freestyle & $1.09 \pm 0.67$ & $1.58 \pm 0.97$ & 2.13 & 0.852 \\
Backstroke & $1.74 \pm 0.56$ & $1.04 \pm 0.12$ & $5.22^{*}$ & $0.034^{*}$ \\
Breaststroke & $1.40 \pm 0.43$ & $1.21 \pm 0.34$ & 2.01 & 0.567 \\
Butterfly & $1.94 \pm 0.60$ & $1.82 \pm 0.42$ & $6.01^{*}$ & $0.018^{*}$ \\
\hline
\end{tabular}

*Significant correlations are flagged at $\mathrm{P}<0.05$

Results on the table above shows that injuries differences between male and female high school swimmers were found significant with respect to Butterfly $(\mathrm{t}=6.01)$ and Back Stroke $(\mathrm{t}=5.22)$, while Crawl $(\mathrm{t}=2.13)$ and Breast Stroke $(\mathrm{t}=2.01)$ were not significant.

The most common musculoskeletal complaint was shoulder pain (16 out of 27 swimmers, 59.2\%), followed by 
knee pain (7 out of 27 swimmers, $25.9 \%$ ), and low back pain (4 out of 27 swimmers, 14.8\%). There was no statistical difference between high school male and female swimmers regarding the incidence of different types of musculoskeletal problems $(\mathrm{p}>0.05)$.

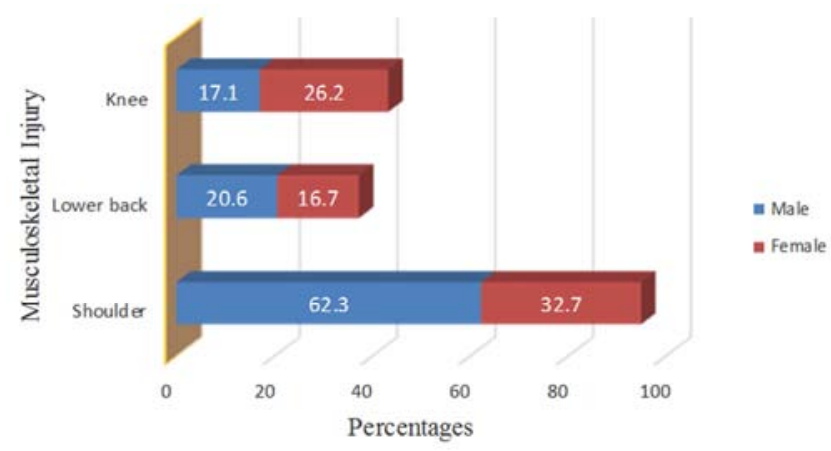

Figure 1. Incidence percentage of musculoskeletal pain in high school male and female swimmers (Take from excel attachment).

\section{Discussion}

Results of the current study revealed that there was no statically significant difference in the number of injuries when comparing high school male and female swimmers $(\mathrm{p}<$ $0.05)[5,10,12]$. Transition to a new level of swimming make swimmers to be at an increased risk for injury, however a gradual decrease in the percentage of injuries in the later years of competition was observed in both gender $[10,12]$.

Most incidences of musculoskeletal pain/injury complaints occurred were reported during the training sessions than the competition period $[2,3,5,10,11,26]$. This study's results showed that upper extremities were the most frequently reported, with prevalence for female $(57.1 \%)$ and male $(62.3 \%)$ swimmers and stress on the shoulder with tendinitis and bursitis $[3,5,13,28]$. These results are in the range found by other researchers previously ranging from 3-67\% $[10,12]$. Whilst missing training or competition result may result in shoulder pain/injury [14, 15, 22] an analysis of shoulder pain by other researchers concluded that these were multifactorial; stroke biomechanics, overuse and fatigue of the shoulder muscles, scapula, and upper back and glenohumeral laxity with subsequent shoulder instability [2, $3,5,8,10,13,16-18,26-28]$.

Knee injury was the second reported source of pain. This was in line with literature which has ranked knee pain/injury second to shoulder pain as a common complaint in competitive swimmers $[1,10,15,19]$. Some authorities have a different notion that knee problems were identified third after spine pain/injuries [10, 12, 14] and other upper extremity injuries as they are associated mainly with in pool or cross training activities [10, 14]. However, the biomechanics of the breaststroke style is different from the other strokes [15, 19-21], in that the upper extremities activity is highlighted which simultaneously start leg stroke with maximal flexion of hip and knee articulations, ankle dorsiflexion, ending with extension and adduction of the mentioned joints $[15,21]$. Therefore, there is recruiting of many muscular groups combined with the movements' repetition leading to overload of the musculoskeletal system generating pain episodes. Increased varus and valgus loads also occur in the knee in addition to rapid knee extension [5]. Knee pain/injuries are a result of repetitive hydrodynamic forces result in cumulative stresses that increase the risk of soft tissue injuries [10]. These hydrodynamic repetitive forces of the breaststroke kick places increased stress on the medial structures of the knee; collateral ligament, patellar facet and synovial lining of the knee joint $[1,10,11,15,19-$ 21].

Spine/lower back was the third reported source of pain/injury in this study. The use of training devices such as fins, kick boards, or pull buoys increase the risk and development of low back pain in competitive swimmers [6, $23,24]$. High intensity and repetitiveness of swimming strokes load the posterior structures of the lumbar spine, resulting in spondylolysis and spondylolisthesis [1, 2, 3]. Muscle strength, endurance, and flexibility protect against low back pain and/or injuries $[6,14,15]$. In the pool, the dolphin kick, utilized for the breast stroke and butterfly stroke, places greater stress on the low back due to the extension stresses on the lumbar spine hence maintaining hyperextension of the lower back to achieve a streamlined position [12, 24, 26, 27]. Therefore, mechanical loading of the spine in competitive sports results in lumbar intervertebral disk degeneration $[4,8,24,25,26]$.

\section{Limitations}

a) Our study used a relatively small sample

b) There may be recall bias when using a questionnaire to injuries sustained during swimming season, since participants can forget to record when the injury occurred

c) Sports injuries usually are characterized by a multifactorial causes, maybe the questions included in the current study's questionnaire were not sufficient to detect possible differences between swimmers with pain and without pain [26].

\section{Conclusion}

The current study showed prevalence of musculoskeletal Injuries in males and females practicing swimming from Higher School of Zimbabwe. Most injuries reported involved the shoulder, the knee and axial spine. Female swimmers were more prone to suffer an overuse injury than their male swimmer counterparts. Musculoskeletal injuries are a common source of pain in competitive swimmers in-pool training, but mostly cross-training also contributes significantly. To minimise pain/injury in swimming, correct stroke technique and stroke alterations need to be practiced and emphasized. Also, much care should be taken for their prevention and early safe return to play. 


\section{Recommendations}

There is need to carry longitudinal studies to confirm similar results with swim teams regionally, followed over several competitive seasons to ensure stability of data and generalisation of findings.

\section{References}

[1] Wanivenhaus F., Fox A. J. S, Chaudhury S, and Rodeo S. A. Epidemiology of Injuries and Prevention Strategies in Competitive Swimmers. Sports Health. May 2012; 4 (3): 246251.

[2] Johnson, Jettery, Frankinh, Sim and Scott S. G. Musculoskeletal injuries in competitive swimmers, Subject review mayo clin proc. 1987; 62: 289-304.

[3] Mc. Mster WC. Shoulder in competitive swimmers. Clinics in Sports medicine, 1999 Vol. 18 (2) 349-357.

[4] Tuppekar R. P. \& Singh S. K. Journal of Sports Science and Technology 2010 Vol. 10 (2S): 154-156.

[5] Venancio B. O., Tacani, P. M. and Deliberato P. 'C. P. Pain prevalence in swimming athletes of São Caetano do Sul. Rev Bras Med Esporte [online]. 2012 Vol. 18 (6); 394-399.

[6] Rechardson, A. B, and Miller J. W. Swimming and the older athlete Clinics in Sports medicine, 1991; 10: 2.

[7] McFarland EG, Wasik M. Injuries in female collegiate swimmers due to swimming and cross training. Clin J Sport Med 1996; 6: 178-182.

[8] [8]. McMaster WC, Troup J. A survey of interfering shoulder pain in United States competitive swimmers. Am J Sports Med 1993; 21: 67-70.

[9] NCAA (2007) Sports Sponsorship and Participation Rates Report 1981/82 \& 2005/06. Indianapolis, IN: National Collegiate Athletic Association.

[10] Sambanis M, Athanailidis I, Sambanis A, Kiritsi O, Tsitas K. A Study of Musculoskeletal Injuries in Greek Male and Female Swimmers. J Nov Physiother 2013; 3: 140. doi: 10.4172/2165-7025.1000140.

[11] Sreekaarini I, Eapen C, Zulfeequer CP. Prevalence of Sports Injuries in Adolescent Athletes. J Athl Enhancement 2014; 3: 5 .

[12] Wolf BR, Ebinger AE, Lawler MP, Britton CL (2009) Injury patterns in Division I collegiate swimming. Am J Sports Med 37: 2037-2042.

[13] Bak K, Fauno P. Clinical findings in competitive swimmers with shoulder pain. Am J Sports Med. 1997; 25 (2): 254-260.
[14] Johnson JN (2003) Competitive swimming illness and injury: common conditions limiting participation. Curr Sports Med Rep 2: 267-271.

[15] Rodeo SA (1999) Knee pain in competitive swimming. Clin Sports Med 18: 379-387, viii.

[16] Rodeo SA. Swimming. In: Krishnan SG, Hawkins RJ, Warren RF, editors., eds. The Shoulder and the Overhead Athlete. Philadelphia, PA: Lippincott, Williams \& WIlkins; 2004: 350.

[17] Rupp S, Berninger K, Hopf T. Shoulder problems in high level swimmers: impingement, anterior instability, muscular imbalance? Int J Sports Med. 1995; 16 (8): 557-562.

[18] Zemek MJ, Magee DJ. Comparison of glenohumeral joint laxity in elite and recreational swimmers. Clin J Sport Med. 1996; 6 (1): 40-47.

[19] Kennedy JC, Hawkins R, Krissoff WB. Orthopaedic manifestations of swimming. Am J Sports Med. 1978; 6 (6): 309-322.

[20] Keskinen K, Eriksson E, Komi P. Breaststroke swimmer's knee: a biomechanical and arthroscopic study. Am J Sports Med. 1980; 8 (4): 228-231.

[21] Vizsolyi P, Taunton J, Robertson G. Breaststroker's knee: an analysis of epidemiological and biomechanical factors. Am J Sports Med. 1987; 15 (1): 63-71.

[22] Brukner P, Khan K. (2006) Clinical Sports Medicine. $3^{\text {rd }}$ Ed. Australia, McGraw-Hill.

[23] Hutson M, Speed S. (2011) Sports Injuries. Oxford, UK: Oxford University Press.

[24] Nyska M, Constantini N, Cale-Benzoor M, Back Z, Kahn G, Mann G. Spondylolysis as a cause of low back pain in swimmers. Int J Sports Med. 2000; 21 (5): 375-379.

[25] Porter RW, Adams MA, Hutton WC. Physical activity and the strength of the lumbar spine. Spine (Phila Pa 1976). 1989; 14 (2): 201-203.

[26] Matheus Oliveira de Almeida, PT, Luiz Carlos Hespanhol, Junior PT, Alexandre Dias Lopes, PT, Prevalence of musculoskeletal pain among Swimmers in an elite national tournament The International Journal of Sports Physical Therapy 2015; 10, (7): 1029

[27] Butler D, Funk L, Mackenzie TA, Herrington LC. Sorting swimmers shoulders: An observational study on swimmers that presented to a shoulder surgeon. Int J Shoulder Surg 2015; 9: 90-3

[28] Kerr ZY, Baugh CM, Hibberd EE, Snook EM, Hayden R, Dompier TP. Epidemiology of National Collegiate Athletic Association men's and women's swimming and diving injuries from 2009/2010 to 2013/2014. Br J Sport Med. 2015; 49 (7): 465-471. 